\title{
BIM modeling for sustainable design and energy efficient construction
}

\author{
Venera Garyaeva* \\ Moscow State University of Civil Engineering, Yaroslavskoe shosse, 26, Moscow, 129337, Russia
}

\begin{abstract}
The goal of sustainable construction is to improve the energy efficiency of a building, which today is a challenge for software developers, builders, owners within the constraints of time, cost, provision and resources. Building functional, sustainable, safe, comfortable and easy-touse buildings will increase consumer demand. The problem of implementing sustainable construction lies in the division of responsibilities and tasks from the relevant specialists. This article explores the role of Building Information Modeling (BIM) in reducing fragmentation among professionals at every stage of construction. The possibility of using a virtual storage of information using BIM is analyzed, which provides easy access to data and their exchange in real time. Thus, BIM provides a professional platform for working in an integrated environment at any stage of the building construction process. When analyzing Russian and foreign sourcesthe prerequisites are being created for the future research required to generate improvements towards sustainable construction.
\end{abstract}

\section{Introduction}

Today, the demand for sustainable construction is growing in connection with the solution of the problems of greening cities, buildings and engineering structures, their ecological reconstruction, eco-friendly restoration of all landscape components, as well as the greening of a wide range of human needs. In some parts of the world, sustainable construction is already widespread. For Russia, the term "sustainable construction" is new, but according to the data, the RF MINSTROY terminology in construction is unified with the international ISO standards. According to the ISO 21930: 2017 standard: Sustainability in construction and civil engineering - Basic rules for the labeling of environmental products on construction products and services, sustainable construction means "design and construction that contributes to the creation and healthy life of sustainable cities, sustainable regions and countries, sustainable society, or ensuring sustainable development of society. "[7]

Sustainable construction is in demand among architects and planners as well as customers and residents. An important task is to solve problems from an economic point of view, with a minimum investment of money and time, as well as increasing productivity. So in this way, with the help of sustainable construction, it is necessary to meet the needs of the consumer.

\footnotetext{
*Corresponding author: garyaev@mgsu.ru
} 
For Russia, this topic is new and has not yet been tested in implementation, but the need for the transition and implementation of sustainable construction in Russia is already understood at the state level.

Implementing this approach to construction requires an efficient integrated implementation process because a building, like a person, has many "integrated systems". If there is a problem with one system, the other system may be more effective. Thus, integration within and between building systems, including interiors, envelopes, structures and mechanical, electrical and plumbing (MEP) systems, to achieve the required characteristics of a sustainable building is essential. Integration of building systems with exterior conditions and functions is also important. The performance of each of these building systems in isolation may vary from the time they are integrated.

The challenges required to ensure sustainable construction are thermal comfort, indoor air quality, acoustics, lighting, architectural and spatial integrity. Building automation, intelligent building systems, structural integrity, earthquake resistance, maintainability, and safety conditions are examples of determining the determinants of system integrity. As part of the requirements for ensuring sustainable construction of a building, tasks must be performed with certain restrictions (limits of acceptability). The limits of acceptability are physiological, psychological, sociological, economic and environmental consequences. The physiological acceptability limit refers to the physical condition of residents such as health, age and performance. The psychological acceptability limit is a function of constructing the expectations of residents about specific tasks in relation to the resource availability of the building. The culture of communication of residents, solidarity, the development of new ethical standards contribute to the formation of requirements for sustainable design and construction. Lower design and construction costs, quick return on investment, increased market value and minimal maintenance and operating costs are some of the determinants of a building's economic acceptability limit. The degree to which each productivity mandate destroys the environment and its resources is the limit of environmental acceptability.

In order to ensure sustainable building construction, decisions made during the design phase when selecting building systems, combining them with the exterior condition and performance, must also take into account the durability, reliability and flexibility of the selected building systems while providing the appropriate construction mandates within the acceptability. The decisions made by the professionals involved in the building design process require an iterative approach.

The same solutions are needed during construction, as well as in the maintenance and operation of the building being sold. Obviously, this approach to building performance, that is, strict adherence to codes and standards, may not be sufficient to ensure sustainable building construction. Probably, in the course of construction should be applied this method to ensure the living conditions of people, eco x and resource properties needed for sustainable development. This approach enables objectivity, clarity, communication, innovation, informed decision-making and professionalism.

This process will require a repository that allows easy access and real-time information exchange. Implementing such a repository requires a non-fragmented design process. However, the construction industry is dominated by ineffective coordination and poor communication among employees. This practice leads to fragmented planning construction problems, poor decision making and delays in the design process, and the high cost of dispute am in the industry.

Essentially, fragmentation between specialists means sharing information. A repository that effectively manages information and knowledge in the building design process will contribute to building sustainability. Information Modeling (BIM) provides such a repository. 


\section{The role of BIM in the processing and management of information to ensure sustainable construction}

Combining building information with the generated 3D building model results in a BIM model. When planning, designing, constructing, maintaining and operating a building, data comes from. This data becomes information when it is collected or documented when it is meaningful and useful to those involved in the construction of the building. Data becomes information in a structured, systematic way of processing that occurs with the understanding, wisdom and experience required to design, construct, maintain and operate a building. Controlling data creation, storage, sharing, distribution, acquisition, and application to an ongoing problem or activity is called information management. The BIM repository is in ndimensions: 3D model, 4D is model with time, 5D is model with cost, and 6D is maintenance and operations. BIM 3D is virtual modeling, building virtualization and associated conditions and location characteristics, detailing walkthroughs, building system assembly and collisions. BIM 4D is about looking at 3D information from a timeline perspective. BIM 4D provides construction planning and management, and mainly visualization of project schedules. BIM 5D provides real-time volume and profit information. BIM 6D compiles all the information obtained during the building construction process. The storage can be software or cloud storage. In addition, BIM cloud storage can link information in many software databases and publish them on the Internet. Everyone involved in the design of the building only needs a username and password to access the server at any time, at any stage of the building's construction (planning, design, construction, maintenance and operation). The BIM repository also provides easy access to the up-to-date information and data needed to efficiently commission a facility. Consider its effectiveness at several stages of building construction.

\section{Planning phase}

Planning activities can include strategic planning and urban design. Strategic planning is the regulatory framework that oversees the development of building concepts in terms of arrays, heights, relationships, connectivity and location. The regulatory framework should ensure ivat sufficient detail in the social, economic, environmental, energy lines and in security, as well as infrastructure and services. The regulation of processes should ensure the longevity of the constructed objects, their functionality and flexibility for foreseeable and non-foreseen future needs.

Urban planning is the process of designing and forming cities, towns and villages on the basis of an established regulatory framework - a master plan. Masterplan and urban design information - in BIM 3D, 4D, 5D and 6D - can be stored in a BIM repository. The information in the BIM repository will be useful in the later stages of building design.

\section{Design phase}

The information generated and stored in the BIM repository during the planning phase governs the actions of the design phase. The main task at the design stage is to ensure the development of design and construction instructions necessary to ensure the functionality, sustainability and suitability of the building, maintenance and operation, and security. The decision made at the design stage must take into account the constructiveness, as well as the efficiency and maintainability of the project in the conditions of limited time and resources. 
Information and communication is essential for an iterative design process. BIM provides a collaborative environment for the exchange of information and data during the design phase.

\section{Construction stage}

Productivity at this stage is very important, as it is at this stage that the ideas and intentions for sustainable construction are realized. In this case, performance refers to the rate at which outputs are generated from a set of inputs. In construction, the term "construction phase productivity" is the amount of construction output generated from a set of inputs (inputs), such as materials, personnel, management, and equipment, used in a given period. These resources are financially supported. High performance generated with the fewest resources, without having to meet cost requirements, is inefficient. The focus on cost in this article reaffirms the importance of considering the challenges in terms of constraints and the durability, reliability, and flexibility of building systems to ensure adequate performance.

To increase productivity during the construction phase, resources (costs) must work in a system that maintains the efficiency of construction activities. These systems represent management methods, material timeliness, and labor efficiency. M Control Methods for functions include data collection and control of production. Improving materials will be better if the planning of materials procurement, as well as the layout of the base and the handling of materials, are improved. Labor efficiency will improve if it improved the safety of work and motivation.

Continuously measuring and evaluating the performance of a construction phase, and adjusting actions necessary to improve efficiency, will improve the process. Improving the management of the system, materials and labor productivity, as well as providing feedback and control to continuously improve the productivity of the construction phases allows the use of BIM at this stage.

\section{Conclusion and future direction of research}

The Basic th idea of this article is that BIM is essential in sharing tasks and working professionals in the design process. This is important because BIM allows you to manage the information obtained during the work of professionals involved in ensuring sustainable construction. Data management is essential in providing a holistic understanding of how a decision made in one building system will contribute to the creation of multiple building systems. In turn, BIM provides a holistic understanding of how a decision made to achieve one of their building performance goals will have multiple challenges to achieve efficiency. The need to provide the required performance targets while ensuring durability, reliability, and flexibility also requires a repository that coordinates all the data generated during the design process.

The BIM repository provides an opportunity for the exchange and distribution of generated information and application of data, showing efficiency to the developer, owner and builders. Documenting the building design process is essential to continually improving construction quality in the industry. BIM storage allows you to exchange information and received data at the stages of building construction.

BIM Repository improves building design productivity by enhancing multiple tasks that are performed during construction phases. These tasks include participating teams, analysis of risk and business development, change management, planning, logistics planning, assessment hundred avail- able constructability analysis, data analysis, coordination of 
design and construction, financial management, by caking of equipment, commissioning, and, security in facility management.

Thus, it is possible to minimize fragmentation during building construction through the use of BIM technologies, but the benefit maximization inherent in BIM will be lacking if the underlying cause of low energy efficiency is still prevalent. The main reason for the low energy efficiency in the building construction process is the social structure of the building construction.

\section{References}

1. MEP BIM SERVICES. [Electronic resource] - Access mode: https://www.advenser.com/mep-bim-services/

2. MEP Building Information Modeling (BIM) Services [ Electronic resource ] - Access mode : https://www.mepbim.com/

3. Lean, BIM, IPD: the unity of opposites in modern construction management practice. [Electronic resource] - Access mode: http://isicad.ru/ru/articles.php?article_num=17220

4. Sustainable building [Electronic resource] - Access mode: https://studfiles.net/preview/6334335/page:20/

5. A.M.Spryzhkov, D.S. Privorotsky, E.V. Privorotskaya. Interdisciplinary integration of BIM and IPD in higher professional education [Electronic resource]. - Access mode: https://cyberleninka.ru/article/v/mezhdistsiplinarnaya-integratsiya-bim-i-ipd-vvysshem-professionalnom-obrazovanii

6. Towards a sustainable future with ISO 21930 [Electronic resource] - Access mode: https://www.iso.org/ru/contents/news/2017/08/Ref2211.html

7. Terminology in construction is harmonized with international ISO standards (ISO) [Electronic resource] - Access mode: http://www.minstroyrf.ru/press/terminologiyu-vstroitelstve-garmoniziruyut-s-mezhdunarodnymi-standartami-iso-iso/

8. Su - Ling, F. (2014) Intellectual Property Rights in Building Infomation Modeling Application in Taiwan. Journal of Construction Engineering and Management, 140.

9. Report. Assessment of the use of BIM technologies in construction. Results of a study of the effectiveness of the use of BIM technologies in investment and construction projects of Russian companies. 2016. [Electronic resource] - Access mode: http://nopriz.ru/upload/iblock/2cc/4.7_bim_rf_otchot.pdf

10. Information modeling of objects of industrial and civil construction. Design, construction, operation [Electronic resource] - Access mode: http: // autodeskcommunity. ru / upload / iblock /656/bim_brochure.pdf.

11. Dmitrieva I.S., Gariaev N.A. Application of simulation modeling for the analysis of architectural and planning solutions for unique objects. In the collection: information systems, technologies and automation in construction. Electronic resource: collection of scientific papers of the Department of ISTAS NRU MGSU. Moscow, 2015.S. 56-60.

12. Gariaev N.A., Gariaeva V.V., Rybina A.V. Development of a simulation model for the analysis of design solutions for remote construction objects from the point of view of providing building materials and structures. Scientific Review. 2015. No. 13. S. 395 398.

13. Garyaev N.A. Design and analysis of information model hotel complex. MATEC Web of Conferences 2016. C. 06007. 
14. Garyaev N.A. Geographically distributed learning network construction industry. Computing in Civil and Building Engineering Proceedings 2014 International Conference. 2014. C. 1578-1585.

15. Garyaev N.A., Gagarin P.V. Modern computational modeling as a stage in the development of the design process. MGSU Bulletin. 2009. No. S1. S. 186-187.

16. Garyaev N.A., Krasnoshchekova A.I., Knyazev A.A. Analysis of the risks arising from the implementation of BIM-technologies in construction organizations. BST: Construction Technique Bulletin. 2018. No. 7 (1007). S. 58-61.

17. Garyaev N.A., Rybina A.V. Simulation model of material and technical support of construction objects. System technologies. 2018. No. 1 (26). S. 142-150.

18. Garyaev P.N. Computer-aided zoning and urban planning. Computing in Civil and Building Engineering Proceedings 2014 International Conference. 2014. C. 1618-1625.

19. Garyaeva V.V. Application of BIM modeling for the organization of collective work on a construction project/ MATEC Web of Conferences 2018. C. 05025. 